\title{
APPLICATION OF BUILDING INFORMATION MODELLING (BIM) IN A RESIDENTIAL PROJECT IN INDIA: BENEFIT-COST ANALYSIS
}

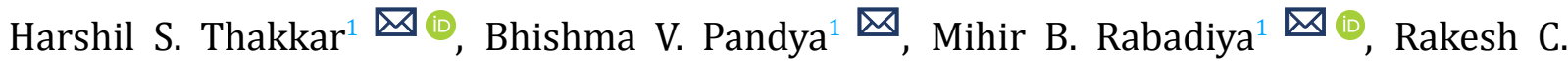 \\ Prajapati $^{1}$ (1) and Dhwani S. Thakkar ${ }^{2}$ (1) \\ ${ }^{1}$ Department of Civil Engineering, L.J. Institute of Engineering and Technology- Gujarat Technological University, India \\ ${ }^{2}$ Department of Civil Engineering, Indus Institute of Technology and Engineering, Indus University, India
}
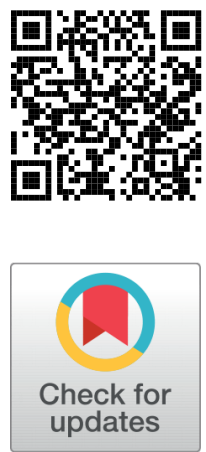

Received 16 June 2021

Accepted 29 June 2021

Published 7 July 2021

Corresponding Author

Harshil S. Thakkar, thakkarharshil

38@gmail.com

DOI $10.29121 /$

ijetmr.v8.i7.2021.981

Funding: This research received no specific grant from any funding agency in the public, commercial, or not-for-profit sectors.

Copyright: (C) 2021 The Author(s). This is an open access article distributed under the terms of the Creative Commons Attribution License, which permits unrestricted use, distribution, and reproduction in any medium, provided the original author and source are credited.

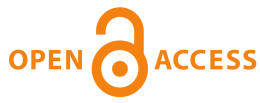

\section{ABSTRACT}

Building information modelling (BIM) is becoming a better-known collaboration process in our construction industry. BIM is a systematic process that amalgamates all the other geometric computer-generated models, or data that creates simulations that can be used for the project manager, owners, facility manager or other parties to look after the project and deliver the project more efficiently. The implementation of BIM in India is still at a nascent stage due to a lack of knowledge of the advantages of BIM. Moreover, there have been only a few case studies conducted in India about BIM; therefore, the principal agenda of this study is to enlighten the readers about the benefits accrued if BIM is applied, in the residential project, before the construction. Hence, the authors had taken a residential project located in Gujarat, India, for a case study. The 3D and 4D models of the project were generated; 8 errors were identified that could have been detected before construction if BIM had been applied. The cost needed to make a BIM model was ₹171,050. Whereas, the amount that could have been saved if BIM was implemented beforehand was discovered as $₹ 246,773$. Consequently, the benefits to cost ratio for two weeks in delay was determined as 1.44. It can be recognised as the benefit of utilising BIM for construction.

Keywords: Building Information Modelling, BIM, Benefits-Cost Analysis, Residential Project, India, Gujarat

\section{INTRODUCTION}

Increment in the fields of urbanization, industrialization, infrastructure projects, increasing population base, the Construction industry sector, and the Real estate sector are recognized as the most important industries in India that play a crucial part in the country's economic growth. One of the BIM study asseverated in an article that it ranked third in terms of contributing to the improvement of the economy (Corbett 
(2021). Moreover, the construction industry plays an essential role in the employment of the workers and has a huge number of workers that work at a low cost. Additionally, the prediction has been done that "the Construction industry in India will become the third-largest global market by 2025" (Corbett (2021). Furthermore, the government has formed a theory that "the Real Estate sector to reach a market size of US\$ 1 trillion by 2030 from US\$ 120 billion in 2017, and the Construction industry is expected to record a compound annual growth rate of $15.7 \%$ to reach $\$ 738.5$ billion by 2022" (Corbett (2021). Despite, this enormous growth and usage of finance, still there is a lack of effective delivery and a lack of management of a certain project by the industry.

Moreover, abundant changes have been ascertained in the construction industry due to technological improvements. Especially, some practical implementations, such as Building Information Modelling (BIM) that may be used for construction management and control. Numerous studies have found that BIM delivers n Dimensional Computer Aided Drawing (CAD) which has not been employed previously in various research. It signifies that "BIM is an effective tool to manage the construction process on time, and its information-oriented interface is a powerful tool for every step-in construction" (Shin et al. (2018). BIM has been used by many industry professionals because of its 3-Dimensional potentiality and to keep a large amount of data under control.

However, many experts have recommended BIM and preferred its practicability, but many of them could not able to explain its proper existence in the real life. Numerous studies have found out its proper use and advantages of using BIM in construction management and for cost control, but most of the studies are practically not possible. Many researchers have embraced the practicability of BIM in academic projects and given a study for future practice. Among them, most of the case studies gave an academic approach therefore it does not lead to the argument in financial terms. Hence, the utility and effect of using BIM in practical life are still uncertain and have not been distinguished.

\subsection{WHAT IS BIM?}

Numerous studies of BIM observed that "BIM can be used as a method of generating and managing information about the building during the various stages of its lifecycle" (G. Lee et al. (2006). It can be implemented as a program to connect all the key stakeholders during the pre-stage, construction stage, and post-construction stage of a project. One of the researcher stated that "BIM is a concept that is going through a powerful study at present in AEC (Architectural, Engineering, and construction) industry" (C. M. Eastman et al. (2011). "The use of computers instead of drawings in building design" was published in AIA journal in the year 1975 and the concept was given by Charles M. Eastman (C. Eastman (1975). 


\subsection{BACKGROUND}

At present, there have been a plenty number of studies that magnify the advantages of BIM in the construction industry. Within one decade there have been more than 900 case studies concerning the implementation of BIM and are issued and also explains that implementing BIM in the construction field is very much advantageous to the owner and client and also could change the world (Volk et al. (2014), Yalcinkaya and Singh (2015). Most of the papers convey significant interest in how to use BIM effectively and a substantial number of attempts have been made to pick out the advantages in construction management (Dakhil et al. (2016).

Few studies have found that BIM technology has been very much beneficial in resource management (S. Lee et al. (2015). In addition, these few articles have also identified that it can also be used for enhancing efficiency, operating efficiency, reduction in the construction errors, rapid work of the construction (Doumbouya et al. (2017) Moreover, numerous studies of BIM stated that "the benefits of BIM are further divided into five categories such as lifecycle cost control, effective construction process, design of quality improvement, decision making support, and risk management" (Terreno et al. (2015). Currently, many case studies explain how the efficiency of the project is being increased by managing the information of the project and reusing the information in the construction fields (Ham et al. (2008).

\subsection{IMPORTANCE OF BIM FOR AEC INDUSTRY}

In the past few years, "BIM has been characterized as a promising tool and approach to address traditional problems inherent in architecture, engineering, and construction(AEC) industries" (Juan and Hsing (2017). Few experts stated that BIM can be used for several purposes depending on the different phases, which includes drawings, interpreting, estimating at the pre-construction stage; disputes, interference, and collision detection at the designing stage; shop drawings and construction sequencing at the construction stage; and later on facility and maintenance management at the post-construction stage (Azhar (2011) .

A few studies observed that as the construction is being carried out by the traditional approach usually leads to disputes between different disciplines during the stage of construction (Mawdesley and Long (2002). This probably arises due to a lack of co-operation across several specialities. In the conventional approach energy consultants, building service designers, management teams, and other professionals are not often included in the early stage of construction. When the structure of the building is after its stage then MEP (Mechanical, Electrical, and Plumbing) consultants are been introduced. By introducing MEP consultants after the completion of the building, it results in facing many problems such as designing a complicated building design, and complications in the installation process. 


\subsection{LITERATURE REVIEW}

As stated by (Giel and Issa (2013) actualized advantages are in abundance, including improved visualization and coordination, a strong return on investments, enhanced efficiencies, minimize clashes between the components of buildings, reduction in mistakes, among others have been connected with BIM implementation on construction projects. BIM's increased benefits have prompted design and construction firms to adopt its deployment at the organizational and project levels Ku and Taiebat (2011), Langar and Pearce (2017). Such advantages of BIM help designers and planners to predict and to control multiple on-site works such as time, the safety of the worker, usage of material, and other resources.

Moreover, (Arayici et al. (2011), Kulatunga et al. (n.d.) discussed that the very nature of the construction industry i.e. shattered nature of the construction industry, underdeveloped research and development capability, risk associated with projects, and others can obstruct the companies capability to apply BIM comprehensively. By applying BIM comprehensively necessitates not only the adoption and deployment of various software or technologies but also replaces the company's work process that is supported by the technologies. On similar factors, (Mayo et al. (2012) specified that adopting BIM comprehensively entails a significant upfront expenditure for the potential adopters. Such significant expenditure may obstruct BIM implementation and operate as a barrier for contractors working in the home building industry. (S. Li and Yu (2019) conferred that in the future the construction industry will face new opportunities and challenges by the implementation of BIM technology and it will be only possible by the government's support to implement the concept of BIM.

(Koc (2006) articulated that introducing 3D CAD has transformed labor incentives drafts into more effective documents. BIM modeling may also combine digital data on time/scheduling (4D) cost/budget management (5D) facilities management (maintenance) (6D) sustainability (life cycle) (7D) occupational safety and health (8D) is supposed to provide a comprehensive approach to the facilities management. ("Mcgraw-hill smart market report" (2021), Machado et al. (2016) stated that the government approach encouraging the adoption of BIM in many building categories as a new standard for project information has a notable push-pull impact. The growth of the Architecture, Engineering, and Construction (AEC) sector has been increased by more than fifty percent on an average from the year 2006 to 2011; as per McGraw hill smart market analysis (2011). BIM has a greater benefit in complex home projects, but the applicability ideas can be used to ordinary housing projects as well (Jia et al. (2017). By the implementation of BIM technology in the construction field will give absolute growth in the future (S. Li and Yu (2019).

(Langar and Bhansali (2018) studied and conceded BIM application at an organizational level was also acknowledged, and the steps were taken by the corporation to address the problems. It also focuses on the impact of BIM implementation on a corporate basis, including the challenges encountered during adoption. Moreover, the application of 5D BIM for cost-benefit analysis of a project for cost-related undertak- 
ing such as scheduling \& supervising of cost of a project. (Kulkarni and Mhetar (2017) and also rectified that the cost control process is very much advantageous with BIM than a traditional method used all over the project duration. Furthermore, (Jununkar et al. (n.d.) applied 4D model-based scheduling simulation has been used to examine the advancement at the site without actually being present at the site and also having the ability to assist in monitoring delays in connection to a planned schedule.

Moreover, (Doumbouya et al. (n.d.) conferred about the value of BIM in construction projects and noteworthy meaning was studied and important concepts of 4D and 5D BIM were also dispensed. Furthermore, by application of BIM, there are substantial organizational impacts for all the stages of construction work. (Mayo et al. (2012) (The BIM Industry Working Group, 2013). (Arayici et al. (2011) conferred that the performance of the project organization has been enhanced by the stakeholder's collaboration by expanding their organizational boundaries during the design and the construction process.

(Mayo et al. (2012) mentioned that in real life, it is assumed that by applying BIM, some expenditure will be offset against the owner's interest, which is not valid for the residential or commercial properties that fall in the small company medium group. Moreover, (Dainty et al. (2015) BIM is expected to drive efficiency, co-operation, and innovation in projects on a large scale, according to BIS, 2015, particularly for construction companies, who account for almost $90 \%$ of all enterprises in the UK. Furthermore, (Georgiadou (2019) explained the actual status of BIM and its adoption in the UK, the feasibility of implementation of BIM used in residential building projects by taking interviews with building professionals and by taking an online survey. Lastly, (Georgiadou (2019) uncovered the specific challenges, benefits, and risks which are found for the application of BIM in the residential sector.

(Jia et al. (2017) stated that under the DBB (Design-Bid-Build) approach, researchers investigated the utility of BIM in the designing phase of residential buildings. The system also includes specialized domains such as site layout, landscapes, architecture, MEP (Mechanical, Electrical, and plumbing), and enhanced decorating, and covers various phases such as building drawing layout, feasibility study, scheme design, and design stage. Based on the BIM adoption value system, they researched with more samples by questionnaire, by taking interviews and on basis of data analysis and conclude the amount of BIM implementation on residential buildings and also to construct a BIM value appraisal model.

(Ham et al. (2008) conferred the idea and function of BIM as a resource to facilitate the pre-design phase, and as well as how the pre-design BIM simulation system may help. Finally, they presented a study that identifies the interconnections between unit space models based on space creation and goal, concluding that BIM adoption in the pre-design phase requires more research. (Jung et al. (2014) conferred that in recent years BIM is developing more on the approach of the construction industry. Due to this, there has been a change in the awareness to the people and as well improves the operations such as saving time, money and increases the client's presentation. 
(Eadie et al. (2013) as per the study, the most primary reason for not applying BIM on working projects is because of lack of experience in the design team and external organizations; and as a result, the benefits of BIM and 3D modeling have still not been addressed on a broad scale in the construction industry. They also expected that through maintaining professional development activities, educational institutions and industry would have more options and would get full financial advantages after BIM adoption.

\section{METHODOLOGY}

Currently, BIM has gained significant attention in the Indian construction industry, despite its awareness, some factors preclude the successful implementation of BIM in small firms (Georgiadou (2019). The research was carried out in a few stages. Firstly, the authors did surveys and comprehensive interviews with experts in the field of BIM who have implemented BIM in a successful project. As a result, the authors identified the projects which would have performed better if BIM was implemented. In the interviews, it was discovered that the Gujarat construction industry has a lack of knowledge of modern technologies and consuming more time in the design stage (Thakkar and Shah (2021). Furthermore, in construction tenure, some projects had involved some extra cost due to the mistakes in drawings. After concerning experts of the field, errors were identified which could be relatively easy to fix in the BIM model. Then, a 3D BIM model and 4D model was created and simulated. The authors also estimated the expected cost and found the quantity of the materials and components. Finally, a benefit-cost analysis was carried with existential data and errors in it that may encourage the industry to build a BIM model frequently.

The study area was selected as a residential building located in Ahmedabad city, Gujarat, India. Due to the requirements of some confidential data, the site was selected such that the builder could share it. The site covered a large area, and it consisted of many facilities to provide; Therefore, BIM could be utilised to enhance the construction experience. Certainly, the use of BIM should be monitored in the whole project as the two most likely benefits are in the maintenance and operating stages (Shin et al. (2018). However, since the site was under construction, only designing and construction of the beginning \& middle stage was feasible to monitor; therefore, the authors considered only these stages. All the necessary information was acquired from the builder and stakeholders of the project. As above mentioned, only beginning stages were considered while making a BIM model; therefore, the available data were sufficient to estimate the cost and to make the pre-schedule for a project.

The research mainly focused on the following areas for the advantages of utilising a BIM: (1) design review, (2) reconstruction \& rearrangements, and (3) detainment in the construction. The design review is to scrutinise the drawings and to identify the errors to eliminate them and to prevent the occurrence of them in the construction stage. Afterwards, reconstruction and rearrangements to gauge any existing 
orders and prevention of reorders as it leads to the delay in construction and increase in cost. Finally, if errors are carried out in the planning, designing and construction phase then the duration of the entire project could be increased. Which later affects the overall cost and the quality of the project delivery is decreased and so the profit. However, these three are not the only measures to cover the total benefits of the project.

\subsection{BIM MODEL}

The BIM model was built based on the information acquired. Furthermore, adjustments for future changes after the initial design was made; such that any further changes in any phase of construction can be adjusted easily in the BIM model too. The 2D AutoCAD drawings were collected from the owners. These drawings were imported to the Autodesk Revit 2021 student version and a 3D model was created. The LOD of the model differs from component to component. As shown in Figure $1 \&$ Figure 2 . Some parts of the model had a LOD of 300 and were accurate, whereas other elements had LOD 200. The higher the LOD the higher information in the model. Furthermore, software was used to compute the quantity of the elements and materials for BOQ. For the number of materials, technical devices were separated into parts: elements that do not have materials embedded, and others that have materials embedded. If there is no information about the material of a component then the main material of components is considered as a plausible material. After computing the quantity, it was compared with the actual site quantity.

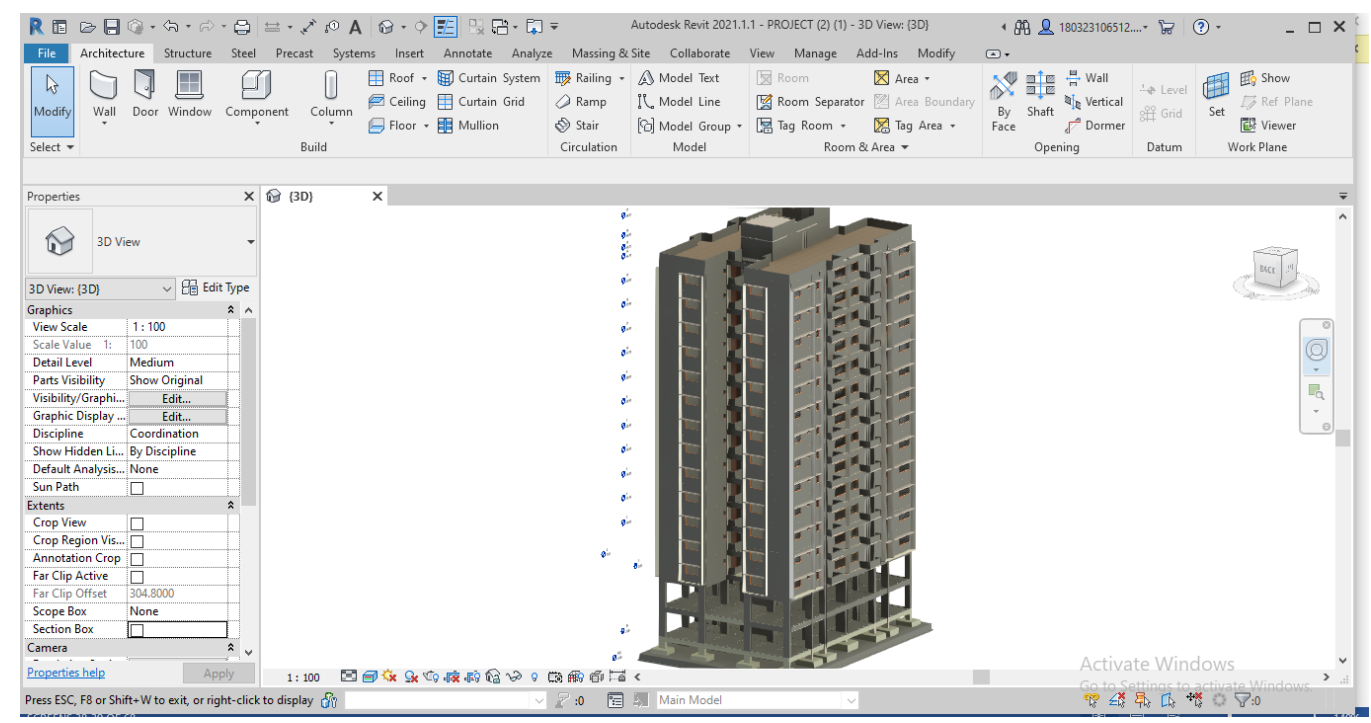

Figure 1 3D BIM model

Figure 2 demonstrates the 4D simulation of the model which was made through integrating the pre-schedule and the 3D model. The pre-schedule of the project was made with the help of experts in the field and coordinating with the project managers 


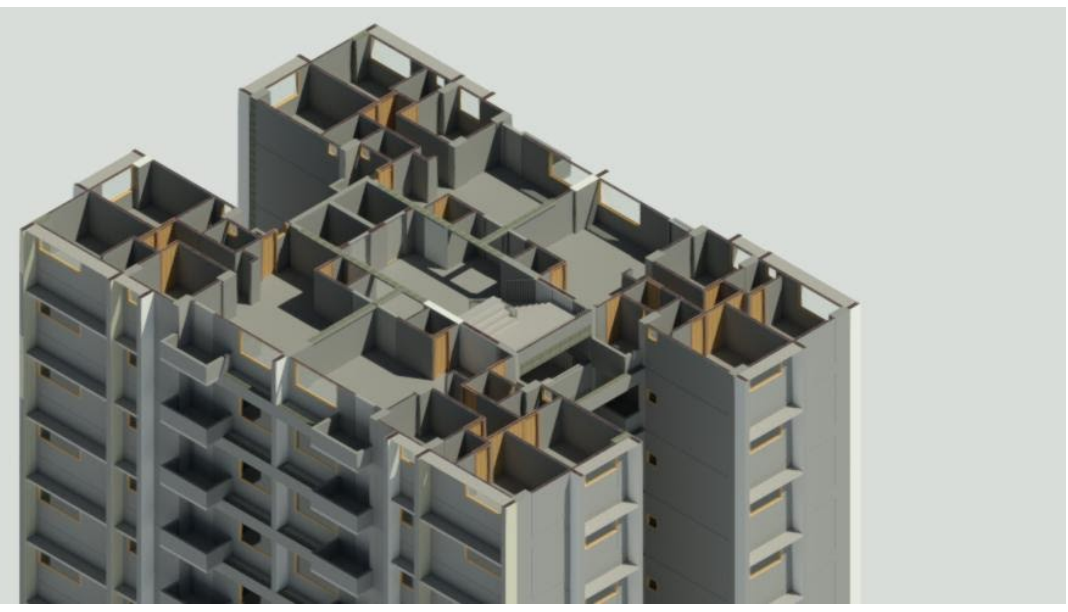

Figure 2 3D BIM Model (2)

of the project. The data was inserted in the Microsoft Excel 2016 spreadsheet. To integrate the data, first, Task ID was given to the elements of the 3D model; then, the same task id was written in the spreadsheet concerning the elements. The model was simulated in the Autodesk Navisworks 2021 and results were noted. Finally, simulated models and completed construction at the site was compared.

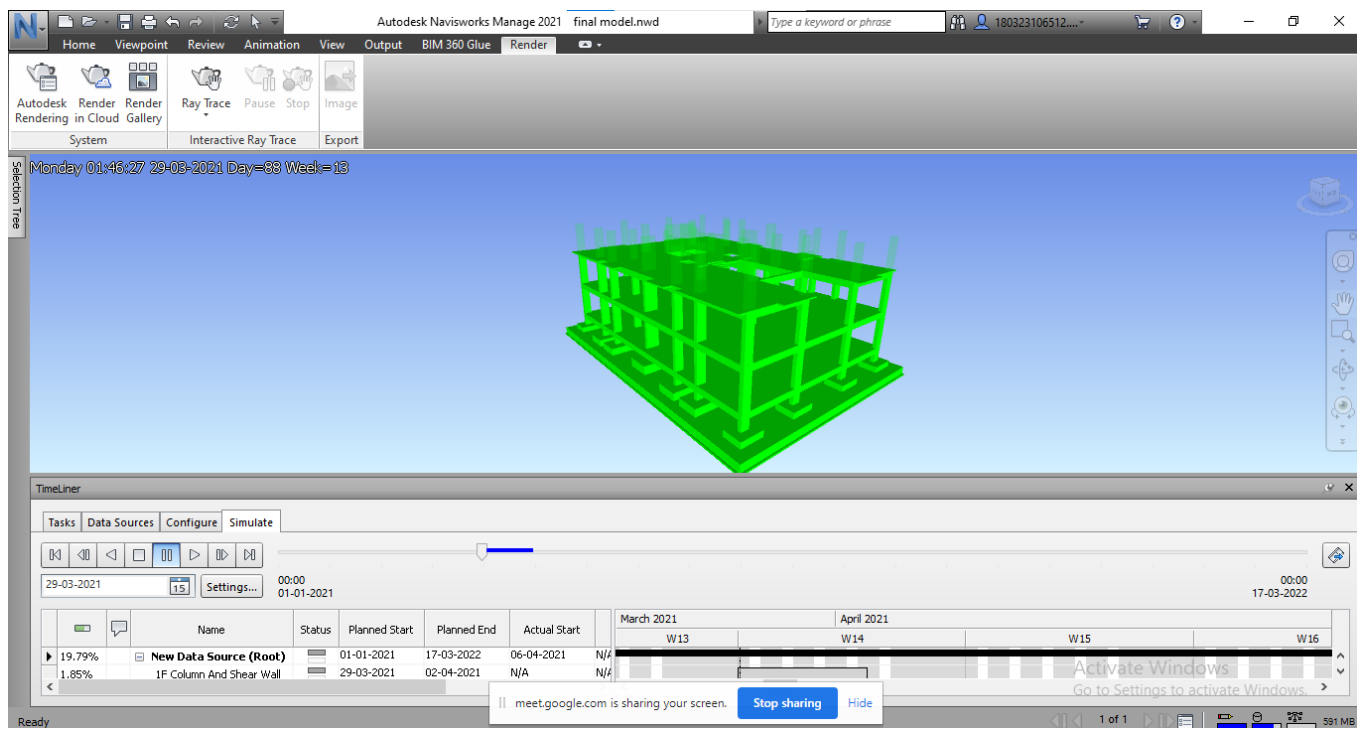

Figure 3 4D BIM Model

\subsection{BENEFIT-COST ANALYSIS}

During the data mining for the project, practitioners discovered the errors which could have been obviated if BIM was employed before the construction. The errors 
discovered by the practitioners were based on the problems occurring in the site during the construction and designing phase of the project which could have been fixed effortlessly if employed by BIM. Generally, the majority of errors in this phase are drawing mistakes, mistakes in dimensions, clash between different components, or over calculation of the same elements. These all faults were thought to be an effortless task for the BIM model. Moreover, the authors estimated the plausible benefits that could be achieved if those mistakes were fixed prematurely. In the end, the benefits over cost ratio were determined. Where the benefits comprised the estimation of the rework quantity of the structural members, cost of the labourers, and cost of the designers and engineers spent to fix the errors; over the total expenditure to make a BIM model.

\section{RESULT AND FINDINGS}

\subsection{IMPLEMENTATION OF THE BIM IN THE FIRM}

Before the implementation of the BIM, the firm was using the general combination of the 2D CAD drawings for executing the work at the site. Sometimes hand drawings were also used to instruct the workers on the site. Due to lack of visualisation of the work, issues were raised and delayed the work which caused an increase in the project cost. As the small enterprises in India still tend to use the traditional method, pre-schedule was not prepared which caused improper planning in the project. Calculations of the quantity take-off were done manually which caused errors in the results of quantity. The firm also lacked the modern equipment to execute the work. Therefore, BIM was explained in brief to the builder and enlightened them about the advantages of BIM to generate a consensus within the company about the BIM. Departmental staff was also introduced to the BIM and how to implement it.

\subsection{DATA COLLECTION OF SITES}

After the thorough literature review for a case study, a block of a residential building from a large project was selected. The drawings were gleaned from the builder to do the case study, and the followings were inferred from the drawings. The selected construction project's cost was around 400 million INR, and the overall project cost was approximately more than 750 million INR. The project plot had a net area of 11043 $\mathrm{m}^{2}$ and comprised six residential blocks of G+13 story, and one block had commercial units till 2nd floor and 11 floors above it were for residential purpose. There was a concerted basement and had an area of $9364.43 \mathrm{~m}^{2}$. Due to the confidentiality agreements, permission for research was given for only one block of the project. B block was taken for the study the built-up area of the B block for G+13 story was 6504 $\mathrm{m}^{2}$. There were 4 households on each floor and each flat had 3-bed rooms, 1 hall, 1 kitchen and 2 balconies. The built-up area of each flat was $76 \mathrm{~m}^{2}$. 


\subsection{DATA COLLECTION OF BIM MODEL}

The 3D model was made from the 2D drawing in Autodesk Revit and quantity take-off was done. For example, it was found out that on the typical floor the total volume of major structural elements is as follows: all the columns had a volume of $32.84 \mathrm{~m}^{3}$, the volume of the beam was $46.38 \mathrm{~m}^{3}$, and the volume of the slab was $49.28 \mathrm{~m}^{3}$. The $4 \mathrm{D}$ model was prepared in the Autodesk Navisworks 2021 after integrating the data from Microsoft Excel 2016. For the schedule, the critical path method was used and the estimated time for completion of a block was found to be 501 days. Whereas, according to the coordinators of the firm "the same amount of work will take at least 540 days to complete" based on their recent completed projects. In scheduling the work considered was: the foundation of a building, RCC structural members of the whole building and walls with the plaster. Later, a 4D model was simulated; when data compared with the actual site data, it was discovered that work done at the project was behind the work supposed to be completed according to the schedule.

After retrieving the results from the 3D and 4D model, the authors identified the 8 errors. The Table 1 depicts all the errors discovered from the model which occurred during the construction process at the site. As it can be interpreted that most of the errors were due to mistakes in the design stages and mistakes while making the CAD drawings, or interference in between the structural elements and MEP elements. These types of errors were easy to fix with the BIM model. Furthermore, as BIM can automatically identify mismatches or interferences, it saves time also.

\begin{tabular}{ccc}
\hline Table 1 Identified errors through BIM model & & \\
\hline Errors & Category & Benefits if fixed \\
Stairs level mismatch & Dimension change & Obviate rework \\
Dimension changes in architectural elements & Dimension change & Obviate rework \\
Clash between structural and MEP elements & Interference simulation & Obviate rework \\
Clash between structural and MEP elements & Interference simulation & Obviate rework \\
Dimensions errors & Dimension change & Obviate rework \\
Abrupt changes in section of walls & Drawing changes & Prevention in delay \\
Lack of stock in inventory & Miscalculation & Prevention in delay \\
Wrong execution of work & Drawing changes & Prevention in delay \\
\hline
\end{tabular}

\subsection{COST ESTIMATION OF BIM MODEL}

Firstly, to estimate the cost, it was worked out to anticipate the requirements of the workers needed to make the BIM model, for collection of the data, and to apply the BIM model at the worksite. To do so, the information gleaned from the firm was used. Information contained man-hour and unit fees of materials required. Then it was decided what the laborers' needed for work. "BIM implementation requires two processes: BIM work and site investigation for BIM implementation" (Shin et al. (2018). For the BIM work, professionals are needed where they are generally termed 
as BIM modellers, BIM coordinators, and BIM managers. Where BIM managers are experienced compared to the BIM modellers who usually creates the BIM model. For supervision of the construction, In India, professional engineers are required where the level of professional engineers at the site are: project manager, senior engineer, junior engineer, and supervisor. Project managers held the highest authority and get paid high when compared to the other engineers. As the level decreases authority and pay grade decreases. The Table 2 below demonstrates the cost of the BIM modellers and professional engineers required to implement the BIM for the research. The cost considered for the professionals was based on the information provided by the construction firm and the BIM experts cost was determined after the information received from the well-known BIM firms in the city. It can be seen, the cost of the creation of a BIM model was ₹171,050. As the data collected was based on the assumption that they are accurate and the rate does not change under different areas to finish the work; So, an extra $10 \%$ was added to the cost as contingency charges (Shin et al. (2018).

\section{Table 2 BIM worker cost estimates}

\begin{tabular}{|c|c|c|c|c|}
\hline \multicolumn{5}{|c|}{ Cost $=($ No. of worker $) \times($ Man-hour $/ 8 \mathrm{~h}) \times($ Daily Wages $)$} \\
\hline Position & Man-hour & No. of workers & Daily wages & Cost \\
\hline $\begin{array}{c}\text { BIM } \\
\text { Manager }\end{array}$ & 40 & 1 & $₹ 7,500.00$ & $₹ 37,500.00$ \\
\hline $\begin{array}{c}\text { BIM } \\
\text { Coordinator }\end{array}$ & 64 & 1 & $₹ 6,000.00$ & $₹ 48,000.00$ \\
\hline BIM Modeler & 56 & 2 & $₹ 5,000.00$ & $₹ 70,000.00$ \\
\hline \multicolumn{4}{|c|}{ Total } & $₹ 155,500.00$ \\
\hline \multicolumn{4}{|c|}{ amount with $10 \%$ allowance } & ₹171,050.00 \\
\hline
\end{tabular}

\subsection{BENEFIT ESTIMATION}

To compute the benefits, the practitioners meticulously reviewed the errors shown in the Table 1 of errors to find how much reconstruction or rework is needed in the planning or construction phase. The authors calculated the extraneous cost which had occurred when BIM was not implemented. These parts were split into two parts: (1) cost of redesigning; (2) cost of reconstruction. In the cost of redesigning, the cost for CAD workers needs changes or errors found in the drawings beforehand. Whereas another cost was for labours and materials required for the reconstruction of certain work.

The total in the above Table 3 illustrates the plausible cost that could have been saved if the BIM was implemented. As it can be inferred from the Table 3 the cost required for the rework in designing was about ₹30,625 with 8 days of work. The days considered for the estimation were decided after concerning the experts. As there are no wages for CAD workers in India, the cost for workers is taken after interviewing the different firms. 
Table 3 Plausible cost of redrawing orders \& re-dimensioning orders saved

\begin{tabular}{|c|c|c|c|c|}
\hline \multicolumn{5}{|c|}{ Incurred Reconstruction Costs Based on Redrawing Orders \& Re-dimensioning orders } \\
\hline \multicolumn{5}{|c|}{ Cost $=($ No. of worker $) \times($ Man-hour $/ 8 \mathrm{~h}) \times($ Daily Wages $)$} \\
\hline No. of workers & Position & Man-hour & Daily wages & Cost \\
\hline 1 & Project manager & 10 & $₹ 5,000.00$ & $₹ 6,250.00$ \\
\hline 1 & CAD operator & 20 & ₹3,000.00 & ₹7,500.00 \\
\hline 1 & $\begin{array}{c}\text { Project } \\
\text { Coordinator }\end{array}$ & 30 & $₹ 4,500.00$ & ₹16,875.00 \\
\hline Total redraw b & $\begin{array}{r}\text { fits that could hav } \\
\text { befo }\end{array}$ & $\begin{array}{l}\text { en saved if B } \\
\text { ad }\end{array}$ & implemented & ₹30,625.00 \\
\hline
\end{tabular}

Due to the rework in designing, there were orders of the reconstruction as well. To calculate the cost for the reconstruction of certain works, the authors split the cost into two parts. In the first part, labour cost was computed for the unit volume of reconstruction; in the second part, materials required for the reconstruction and rate of the materials for the unit volume of the same work. The cost of the material was taken from the schedule of rates (SOR) of the Uttar Pradesh Public Work Department (UPPWD (2021) 2020. Because the latest schedule of rates from Gujarat government was not published yet. SOR of (UPPWD (2021)is also considered the standard in India. For the rate of the labour, SOR was taken as reference only as in the SOR labour rates vary with different specifications of work. So, with guidance from the experts, the labour rate was computed. The Table 4 below illustrates the cost determined for reconstruction. The fees of the labours incurred due to the rework were found to be ₹78,374. The total amount of the materials was found to be ₹135,330. The total of both costs was ₹213,704 which could have been saved and the amount could have been spent in other productive activities if BIM was employed.

In India, there are no standard provisions for liquidity damages for a residential building; therefore, some well-established enterprises were interviewed to know the charges of liquidated damages. The results ascertained that the liquidity damage in Gujarat differs from work to and company to company. Generally, 8-10\% of the total construction cost is for the maximum legal delay of up to 200 days. The liquidity damage for the research of this study was taken as $1 \%$ for delay in work every 2 week, because the firm associated with the project had accounted for $10 \%$ liquidity damage up to 150 days. So, delay in the work for every 2 weeks increases the $1 \%$ cost in the project. So, if the errors demonstrated in the Table 1 had been fixed before the construction, then $1 \%$ would have been saved every 2 weeks. Table 5 below demonstrates plausible liquidity damage costs after each month. To validate the research, the liquidity damage was calculated for those errors only since the cost was considered only of the errors found from the model (Shin et al. (2018). There were no other costs calculated as an opportunity cost rather than liquidated damages. Although it may be a biased approach to calculate the opportunity cost, but it was better to consider a small area than to a large extent in the project amount. 


\begin{tabular}{|c|c|c|c|}
\hline Error & & & Estimate \\
\hline Abrupt changes in section of walls & & ction & $\begin{array}{r}\text { Estimate }= \\
(\text { Volume }) \times \\
\text { (Unit rate) }\end{array}$ \\
\hline Stairs level mismatch & & ction & \\
\hline $\begin{array}{l}\text { Clash between structural and MEP } \\
\text { elements }\end{array}$ & & ction & \\
\hline \multicolumn{4}{|c|}{ Labour cost estimate due to reconstruction } \\
\hline Construction & Unit fee & Volume $\left(\mathrm{m}^{3}\right)$ & Estimate \\
\hline Demolition of walls & ₹ 600.00 & 6.21 & $₹ 3,726.00$ \\
\hline Recasting of the walls & ₹800.00 & 6.21 & $₹ 4,968.00$ \\
\hline Demolition of the stairs & $₹ 4,500.00$ & 3.89 & $₹ 17,505.00$ \\
\hline Recasting of the stairs & $₹ 3,500.00$ & 3.89 & $₹ 13,615.00$ \\
\hline $\begin{array}{c}\text { Demolition of the structural } \\
\text { element }\end{array}$ & $₹ 4,500.00$ & 4.82 & $₹ 21,690.00$ \\
\hline $\begin{array}{l}\text { Recasting of the structural } \\
\text { elements }\end{array}$ & $₹ 3,500.00$ & 4.82 & $₹ 16,870.00$ \\
\hline \multicolumn{2}{|l|}{ Subtotal } & \multicolumn{2}{|c|}{ ₹78,374.00 } \\
\hline \multicolumn{4}{|c|}{ Material cost estimate due to reconstruction } \\
\hline Construction & Unit fee & Volume $\left(\mathrm{m}^{3}\right)$ & Estimate \\
\hline Recasting of the walls & $₹ 3,500.00$ & 6.21 & $₹ 21,735.00$ \\
\hline Recasting of the stairs & ₹13,042.00 & 3.89 & ₹50,733.38 \\
\hline $\begin{array}{l}\text { Recasting of the structural } \\
\text { elements }\end{array}$ & ₹13,042.00 & 4.82 & ₹ $62,862.44$ \\
\hline \multicolumn{2}{|l|}{ Subtotal } & \multicolumn{2}{|c|}{ ₹135,330.82 } \\
\hline \multicolumn{2}{|c|}{ Total reconstruction charge because of rework } & \multicolumn{2}{|c|}{ ₹213,704.82 } \\
\hline
\end{tabular}

Table 5 Liquidity risk depending on construction time delays

\begin{tabular}{ccccc}
\hline Delay & Initial Cost & Liquidity Damage (\%) & Liquidated Damage & Total \\
\hline 2 weeks delay & & $1 \%$ & $₹ 2,443.30$ & $₹ 246,773.12$ \\
4 weeks delay & $₹ 244,329.82$ & $2 \%$ & $₹ 4,886.60$ & $₹ 249,216.42$ \\
6 weeks delay & $3 \%$ & $₹ 7,329.89$ & $₹ 251,659.71$ \\
\hline
\end{tabular}

\subsection{BENEFITS TO COST RATIO}

Finally, based on previously carried out estimates, the benefits cost ratio was determined. This ratio shows the benefits that could have been gained if BIM was successfully implemented in the designing and planning phases. The cost required to deliver the BIM model for the project, to fix the errors, was ₹ 171,050 with $10 \%$ allowance. Whereas, the cost to fix the mistakes was ₹246,773. Because certain mistakes might have caused the delays in the project, liquidity damage was also added to the cost that could have been saved. TheTable 6 of b/c ratio below illustrates the final benefits to the cost ratio. It can be estimated that a $1.44 \mathrm{~b} / \mathrm{c}$ ratio with a two weeks delay. 
Table 6 BenefitstoCostratio fordifferentliquidity damage

\begin{tabular}{cccccc}
\hline BIM Cost & $\begin{array}{c}\text { Design } \\
\text { Rework } \\
\text { Benefits }\end{array}$ & $\begin{array}{c}\text { Construction } \\
\text { Rework } \\
\text { Benefits }\end{array}$ & $\begin{array}{c}\text { Liquidated } \\
\text { Damage } \\
\text { Benefits }\end{array}$ & $\begin{array}{c}\text { Total } \\
\text { Benefits }\end{array}$ & B/C \\
\multirow{2}{*}{ ₹171,050.00 } & $₹ 30,625.00$ & $₹ 213,704.82$ & $₹ 4,886.60$ & $₹ 249,216.42$ & 1.46 \\
\hline
\end{tabular}

\subsection{LIMITATIONS}

BIM implementation will grow more favorable in the near future, however with those benefits there come certain restrictions. Firstly, the student's point of view on the research and education of BIM plays the main role in the implementation of BIM. If there is a lack of interest and knowledge there might be possible that the use of BIM might get reduced. Secondly, implementing BIM technology at some small projects might affect the financial situation of the project and also if the traditional method has been applied by the workers then there are equally likely chances of having disputes between the two workers. Moreover, implementing BIM technology requires a huge expenditure in the software and training as well as the program's capability to function. It also necessitates the purchase of a software license to operate the works. Furthermore, it should have awareness and proper education for the use of the software. Due to a shortage of finances, this is sometimes tough to finance, and it is even more challenging for SMEs. (Alwan (2016) said that many housing companies lack the resources to use BIM in the building industry.

Moreover, there also comes an unwillingness to change the traditional method and the fear of implementing BIM due to its high investment. Especially, for some of the housing associations that believe to reduce the overall cost of the construction rather than the Life cycle assessment of the building. Furthermore, demand in the mind of clients also reduces because of the heavy investment and also not realizing the exact value the BIM can provide, which is because of lack of knowledge and capabilities. Sometimes the BIM includes a huge number of data that are not required to some stakeholders and due to this, there are chances of getting errors in entering data or in the interpretation of data. Moreover, the advantages of BIM vary depending on the location and type of work. Because of the differences in cost of materials and labor, the BIM may be beneficial in one place but not in another. Finally, it indicates that the main limitation of not implementing the BIM technology in construction fields is because of the project team's and external organization's lack of competence.

\section{CONCLUSION}

This research was aimed to find the financial gains that could be achieved and how project delivery could be improved if BIM is used to execute the plan in the initial phases of the residential project in India. Although the selected project site 
was located in Ahmedabad, it showed similarities with the other residential projects located in the state. The past studies regarding the Application of BIM in India mostly conducted surveys or interviews with the experts to investigate the benefits of BIM. However, this research was to identify the benefits that could be achieved in the real case of a project; where BIM was implemented before construction.

The 8 errors were discovered by the authors from the BIM model. The errors were relatively simple to detect before construction if BIM was implemented, as some errors were like the interference in between the structural elements with MEP elements, dimension errors, change in location points of the components, etc. In the project, the BIM was not employed at the construction site; therefore, reworks had to be done for some of the mistakes. Reworks were worked out in the designing phase and construction phase; consequently, it caused an increase in cost and risk.

After discovering the errors, the cost to build the BIM model and the cost to fix the errors were computed. Then after scrutinising the data, the benefits to the cost ratio was determined. The $\mathrm{B} / \mathrm{C}$ ratio for the selected project was found to be 1.44 with a delay of 2 weeks in construction. This ratio helps to conclude that if BIM was implemented beforehand then the cost could have been significantly reduced, and the project could have been delivered efficiently without any delays. However, the study was not governed to the large extent, and an assumption was made that the selected project is the paradigm of all the construction projects in the whole country. Also, some assumptions were made while computing the cost of some work too; because, there are no standard guidelines from the government of India to successfully implement the BIM. These all may be the factor to decide whether all projects will have the same impact if they use the BIM model.

Finally, implementing the BIM process is challenging in India, as this technique is still at its incipient stages in India, but if the challenges prevailed by builders, contractors, architects and project managers then it could have a significant impact on the Indian construction industry. Further study, to the large extent or in the large projects will help the Indian construction industry, and the construction industries over the globe which shares similar characteristics with the Indian construction industry to comprehend the benefits of BIM if applied successfully.

\section{ACKNOWLEDGEMENTS}

Firstly, we would choose to express our appreciation to the firm, and to their engineers who gave us these crucial information and data. We would also like to express our deepest gratitude to our experts for giving up their time for the interviews.

\section{REFERENCES}

Alwan, Z. (2016). BIM performance framework for the maintenance and refurbishment of housing stock. Structural Survey, 34(3), 242-255. Retrieved from https://dx.doi.org/ 10.1108/ss-03-2015-0018 10.1108/ss-03-2015-0018 
Arayici, Y., Coates, P., Koskela, L., Kagioglou, M., Usher, C., \& O’Reilly, K. (2011). Technology adoption in the BIM implementation for lean architectural practice. Automation in Construction, 20, 189-195. Retrieved from https://dx.doi.org/10.1016/j.autcon.2010.09 .016 10.1016/j.autcon.2010.09.016

Azhar. (2011). Building Information Modeling (BIM): Trends, Benefits, Risks, And Challenges For The AEC Industry. Leadership And Management In Engineering, 11(3), 241-252.

Bisbimstrategyreport.Pdf. (N.D.). (2021). Retrieved from Https://Www.Cdbb.Cam.Ac.Uk/ System/Files/Documents/Bisbimstrategyreport.Pdf

Bpe_2015_Statistical_Release, \& Pdf. (2021). Retrieved from Https://Assets.Publishing .Service.Gov.Uk/Government/Uploads/System/Uploads/Attachment_Data/File/ 467443/Bpe_2015_Statistical_Release.Pdf

Corbett. (2021). Construction Industry In India | Overview \& Statistics | Maier+Vidorno. Maier And Vidorno. Retrieved. Retrieved from Https://Www.Maiervidorno.Com/ Industry-Expertise/Construction/

Dainty, A., Leiringer, R., Fernie, S., \& Harty, C. (2015). Don't Believe The (BIM) Hype: The Unexpected Corollaries Of The UK "BIM Revolution. Retrieved from Http://Hub.Hku.Hk/ Handle/10722/215773

Dakhil, A., Underwood, J., \& Shawi, M. (2016). BIM Benefits-Maturity Relationship Awareness Among UK Construction Clients.

Doumbouya, L., Gao, G., \& Guan, C. (n.d.). Adoption Of The Building Information Modeling (BIM) For Construction Project Effectiveness: The Review Of BIM Benefits. American Journal Of Civil Engineering And Architecture, 6.

Doumbouya, L., Guan, C. S., Gao, G., \& Pan, Y. (2017). Application Of BIM Technology In Design And Construction: A Case Study Of Pharmaceutical Industrial Base Of Amino Acid Building Project. 16th International Scientific Conference Engineering For Rural Development. Retrieved from Https://Doi.Org/10.22616/Erdev2017.16.N338

Eadie, R., Browne, M., Odeyinka, H., McKeown, C., \& McNiff, S. (2013). BIM implementation throughout the UK construction project lifecycle: An analysis. Automation in Construction, 36, 145-151. Retrieved from https://dx.doi.org/10.1016/j.autcon.2013.09.001 10.1016/j.autcon.2013.09.001

Eastman, C. (1975). The Use Of Computers Instead Of Drawings In Building Design. AIA Journal, 63-63.

Eastman, C. M., Eastman, C., Teicholz, P., Sacks, R., \& Liston, K. (2011). BIM Handbook: A Guide To Building Information Modeling For Owners, Managers, Designers, Engineers And Contractors.

Georgiadou, M. C. (2019). An Overview Of Benefits And Challenges Of Building Information Modelling (BIM) Adoption In UK Residential Projects. Construction Innovation., 19, 298-320. Retrieved from Https://Doi.Org/10.1108/CI-04-2017-0030

Giel, B. K., \& Issa, R. R. A. (2013). Return on Investment Analysis of Using Building Information Modeling in Construction. Journal of Computing in Civil Engineering, 27(5), 511-521. Retrieved from https://dx.doi.org/10.1061/(asce)cp.1943-5487.0000164 10.1061/ (asce)cp.1943-5487.0000164

Ham, N. H., Min, K. M., Kim, J. H., Lee, Y. S., \& Kim, J. J. (2008). A Study On Application Of BIM (Building Information Modeling) To Pre-Design In Construction Project. Third International Conference On Convergence And Hybrid Information Technology, 1, 42-49. Retrieved from Https://Doi.Org/10.1109/ICCIT.2008.190

Jia, J., Sun, J., Wang, Z., \& Xu, T. (2017). The Construction Of BIM Application Value System For Residential Buildings' Design Stage In China Based On Traditional DBB Mode. Pro- 
cedia Engineering, 180, 851-858. Retrieved from Https://Doi.Org/10.1016/J.Proeng .2017.04.246

Juan, Y.-K., \& Hsing, N.-P. (2017). BIM-Based Approach to Simulate Building Adaptive Performance and Life Cycle Costs for an Open Building Design. Applied Sciences, 7(8), 837837. Retrieved from https://dx.doi.org/10.3390/app7080837 10.3390/app7080837

Jung, J., Hong, S., Jeong, S., Kim, S., Cho, H., Hong, S., \& Heo, J. (2014). Productive Modeling For Development Of As-Built BIM Of Existing Indoor Structures. Automation In Construction., 42, 68-77. Retrieved from Https://Doi.Org/10.1016/J.Autcon.2014.02.021

Jununkar, S. M., Aswar, D. S., \& Mittapalli, D. L. (n.d.). APPLICATION OF BIM AND CONSTRUCTION PROCESS SIMULATION USING 5D BIM FOR RESIDENTIAL BUILDING PROJECT., $4(7), 5-5$.

Koc, E. (2006). Extended review of Shakespeare, Einstein and the Bottom Line: The Marketing of Higher Education by D.L. Kirp. On the Horizon, 14, 19-21. Retrieved from https:// dx.doi.org/10.1108/10748120610648435 10.1108/10748120610648435

Ku, K., \& Taiebat, M. (2011). BIM Experiences And Expectations: The Constructors. Retrieved from Https://Doi.Org/10.1080/15578771.2010.544155

Kulatunga, K. J., Amaratunga, R. D. G., \& Haigh, R. (n.d.). CONSTRUCTION INNOVATION: A LITERATURE REVIEW ON CURRENT RESEARCH. 10.

Kulkarni, S. B., \& Mhetar, G. (2017). Cost Control Technique Using Building Information Modeling (BIM) For A Residential Building., 10, 7-7.

Langar, S., \& Bhansali, S. (2018). Building Information Modeling (BIM) Implementation In The Residential Sector.

Langar, S., \& Pearce, A. R. (2017). Implementation Trends for Rainwater-Harvesting Technologies and Strategies and Their Relationship with Building Information Modeling. Journal of Architectural Engineering, 23(1), 04016016-04016016. Retrieved from https://dx.doi.org/10.1061/(asce)ae.1943-5568.0000228 10.1061/(asce)ae .1943-5568.0000228

Lee, G., Sacks, R., \& Eastman, C. M. (2006). Specifying parametric building object behavior (BOB) for a building information modeling system. Automation in Construction, 15(6), 758-776. Retrieved from https://dx.doi.org/10.1016/j.autcon.2005.09.009 10.1016/ j.autcon.2005.09.009

Lee, S., Tae, S., Roh, S., \& Kim, T. (2015). Green Template for Life Cycle Assessment of Buildings Based on Building Information Modeling: Focus on Embodied Environmental Impact. Sustainability, 7(12), 16498-16512. Retrieved from https://dx.doi.org/10 $.3390 /$ su71215830 10.3390/su71215830

Li, J., Afsari, K., Li, N., Peng, J., Wu, Z., \& Cui, H. (2020). A review for presenting building information modeling education and research in China. Journal of Cleaner Production, 259, 120885-120885. Retrieved from https://dx.doi.org/10.1016/j.jclepro.2020.120885 10.1016/j.jclepro.2020.120885

Li, S., \& Yu, Y. (2019). Application Of BIM Technology In Calculation Of A Residential Building. IOP Conference Series: Earth And Environmental Science, 330, 22071-22071. Retrieved from Https://Doi.Org/10.1088/1755-1315/330/2/022071

Machado, M., Underwood, J., \& Fleming, A. (2016). Implementing BIM to Streamline a Design, Manufacture, and Fitting Workflow. International Journal of 3-D Information Modeling, 5(3), 31-46. Retrieved from https://dx.doi.org/10.4018/ij3dim.2016070103 10 .4018/ij3dim.2016070103

Mawdesley, M. J., \& Long, G. (2002). Prefabrication For Lean Building Services Distribution. 10th Annual Conference Of The International Group For Lean Construction. Retrieved 
from Https://Www.Iglc.Net/Papers/Details/197

Mayo, G., Giel, B., \& Issa, R. (2012). BIM Use And Requirements Among Building Owners., 349-356. Retrieved from Https://Doi.Org/10.1061/9780784412343.0044

Mcgraw-hill smart market report. (2021). Retrieved from Http://Images.Autodesk.Com/ Latin_Am_Main/Files/Mcgraw-Hill_Construction_Bim_Smartmarket_Report _December_2008.Pdf

Shin, M. H., Lee, H. K., \& Kim, H. Y. (2018). Benefit-Cost Analysis Of Building Information Modeling (BIM) In A Railway Site. Sustainability, 10(11). Retrieved from Https://Doi.Org/ 10.3390/Su10114303

Terreno, S., Anumba, C. J., Gannon, E., \& Dubler, C. (2015). The Benefits Of BIM Integration With Facilities Management: A Preliminary Case Study., 675-683. Retrieved from Https://Doi.Org/10.1061/9780784479247.084

Thakkar, H., \& Shah, V. A. (2021). BARRIERS TO IMPLEMENTATION OF LEAN CONSTRUCTION TECHNIQUES IN GUJARAT CONSTRUCTION INDUSTRY. International Journal of Engineering Technologies and Management Research, 8(4), 17-24. Retrieved from https:// dx.doi.org/10.29121/ijetmr.v8.i4.2021.905 10.29121/ijetmr.v8.i4.2021.905

UPPWD. (2021). C_202006261152416618. Retrieved from Http://Www.Uppwd.Gov.In/ Site/Writereaddata/Uploadnews/Pdf/C_202006261152416618.Pdf

Volk, R., Stengel, J., \& Schultmann, F. (2014). Building Information Modeling (BIM) for existing buildings - Literature review and future needs. Automation in Construction, 38, 109-127. Retrieved from https://dx.doi.org/10.1016/j.autcon.2013.10.023 10.1016/ j.autcon.2013.10.023

Yalcinkaya, M., \& Singh, V. (2015). Patterns and trends in Building Information Modeling (BIM) research: A Latent Semantic Analysis. Automation in Construction, 59, 68-80. Retrieved from https://dx.doi.org/10.1016/j.autcon.2015.07.012 10.1016/j.autcon .2015.07.012 